\title{
Psychiatry in the Spinal Injuries Unit
}

Fiona K. Judd, M.B.B.S., D.P.M., M.R.A.N.Z.C.P., and Douglas J. Brown, M.B.B.S., F.R.A.C.P.

Spinal Injuries Unit, Austin Hospital, Heidelberg, Vic. 3084, Australia

\section{Introduction}

The recognition that a significant number of patients with spinal cord injury (SCI) have diagnosable psychiatric disorders, and the need for comprehensive physical, psychological and social rehabilitation of SCI patients have firmly established the need to include the psychiatrist as a member of the multidisciplinary treatment team (Judd and Burrow, 1985). Comprehensive psychiatric assessment in the early post injury period is indicated for all SCI patients and their families. Subsequently, the psychiatrist may be directly involved in the treatment of patients with identified psychiatric disorders, or in the psychotherapeutic management of patients and their families. However, much of the psychiatrist's work within the spinal injuries unit will involve secondary consultation, guiding other members of the treatment team in their interactions with patients and their families and in planning rehabilitation. Various members of the treatment team may take primary responsibility for the psychosocial management of the patient, relying on the psychiatrist as a consultant.

\section{Psychiatric assessment}

The psychiatrist should assess all patients admitted with a SCI at the earliest opportunity, to determine the patient's personality structure and capacity to deal successfully with his disability. This assessment of the patient's habitual coping style and readiness to co-operate with and accept medical treatment assists with the planning of optimal management.

Patients when threatened by illness, react according to characteristic habitual methods and attitudes which are determined by personality traits and past experience. Anxious over-concern, inappropriate independence, dependent demanding behaviour and hostility are commonly observed inappropriate responses.

Early psychiatric assessment assists the staff to understand the patient's personality and needs, and allows the treating team to deal with the patient's problems in an appropriate and positive way. When the staff understand the 
meaning of the injury for the individual patient they can decide to what extent they can help the patient by satisfying his needs for special attention, setting or relaxing certain limits and facilitating or modifying the patient's defensive efforts (Kahana and Bibring, 1964).

\section{Psychiatric illness}

Between $20-40^{\circ}{ }_{0}$ of patients in medical wards of hospitals have a diagnosable psychiatric disorder; it is suggested that the prevalence is even greater in spinal cord injury units (Mayou and Hawton, 1986). It is important to determine accurately the prevalence of psychiatric morbidity in spinal injury units, especially to distinguish accurately 'appropriate distress' and psychiatric disorder. Currently available measures have not been validated for use with SCI patients. It is likely that such measures fail to detect 'masked' depression and anxiety in patients who deny their emotional distress, or may over-estimate disorder because patients have physical causes for somatic symptons thought to substantiate a diagnosis of emotional disorder. It is of particular importance to determine the prevalence of depressive illness, which may adversely affect both the rehabilitation programme and the achievement of long-term rehabilitation goals. While it is accepted that many, if not all spinal cord injured patients become despondent, early studies have demonstrated significant depressive illness in only a minority (Judd et al., 1987; Fullerton et al., 1980; Lawson et al., 1978).

Future research is required to determine accurately the prevalence of psychiatric disorders in spinal cord injured patients, to establish the reliability and validity of currently used clinical assessments and diagnostic criteria, to evaluate the utility of laboratory tests such as the dexamethasone suppression test, and to determine which types of disorder benefit from early recognition and treatment.

\section{Psychiatry and rehabilitation}

Modern rehabilitation must consider not only the patient's physical condition and vocational aptitude, but also his psychologic potential, i.e. which activities potentially promise the patient fulfilment of his emotional needs. The final outcome of rehabilitation will depend heavily on the patient's capacity to deal successfully with his disability. The focus of psychological intervention will be those variables which are significant in the adaptational process involved in rehabilitation. Fundamental to coping with permanent disability is the awareness and acceptance by the individual that he is not sick, but different. While he sees himself as sick, the individual exhibits appropriate illness behaviour and has appropriate expectations of getting better. Once he recognises that he is different, he may function as an individual with distinctive needs, problems and ways of adapting (Adams and Lindemann, 1974). A clear picture of the individual's self image is thus essential for effective assistance in rehabilitation. Maintenance of self esteem is a crucial task in the adaptation process. The individual's sense of movement towards an image of himself in the future is essential to this. Those assisting the patient in rehabilitation must understand the sources and supports of this image. 
Difficulties experienced in coping with the stress of SCI may be expressed in various forms. Often non-compliance with treatment, being a 'difficult patient', excessive and poorly explained pain or other somatic symptoms are manifestations of depressive illness, anxiety and maladaptive coping skills. The psychiatrist may help the patient deal with the stress in more adaptive ways and may assist staff to understand the reasons for the patient's behaviour and symptoms, allowing them to facilitate changes in his behaviour and adaptation.

\section{The family of the SCI patient}

The family of the injured person must also make major adaptive changes, and family adjustment should be considered to be a part of the rehabilitation process. Early assessment of family functioning and coping is indicated. Influencing family adaptation positively is of considerable importance both for the family and its disabled member. The family's emotional state, reaction to and expectations of the disabled member, all influence the individual's own attitude to his disability.

In time of crisis, families tend to cope by exaggerating pre-existing roles and ways of coping. Adjusted families show positive coping strategies and re-orient their lives to encompass new disability-related events (Power, 1985).

Where pre-existing family conflict, poor family communication and inadequate problem solving skills are identified, early intervention to improve family functioning is indicated. When family members experience difficulty in dealing with their injured member, individual or family therapy may facilitate adaptation with benefit to both.

\section{Patients and research}

Specialised psychiatric assessment of patients participating in the development of new specialised and research procedures, e.g. functional neuromuscular stimulation is required. The psychological and social effects of participating in a programme in which personal benefits are possible but not guaranteed are of importance both to the patient's well being and to research success. The patient's ability to tolerate uncertainty and cope with failure of the procedure must be ensured. Patients should be screened to maximise the appropriate involvement of research candidates. Characteristics associated with inappropriate participation might include major psychiatric disorder, alcohol or drug abuse, poor coping skills, interpersonal relationship problems, excessive denial of disability and unrealistic expectations of research benefits.

\section{Suicide and euthanasia}

The 'right to die' has achieved legal and social prominence in many countries; often the debate has involved patients with spinal cord injury. Passive euthanasia may be a consideration early in the acute phase following SCI for patients with spinal cord lesions above $\mathrm{C} 4$ or those with other severe injuries, particularly head injuries. At this time the potential for a productive, personally valued and meaningful life will be considered. The personal values of the treating medical 
and nursing staff, the ways in which they identify with the patient and the attitude of the patient's family and friends must be considered as factors influencing such decisions.

Later in the acute phase, active rather than passive euthanasia may be requested by the ventilator dependent patient and those with a lesion at C4 or C5 where suicide is not an option. Questions such as 'should the ventilator dependent patient be allowed to die' are no different from 'should the C4 or C5 quadriplegic be assisted to die'. The same assessment as is made of other patients expressing suicidal ideation is required.

\section{Long term care}

The long term psychiatric sequelae of SCI have been poorly studied. Primary and/or secondary psychiatric consultation may be required to deal with individual and family problems which develop as a result of the disability, or preexisting problems which are exacerbated by the disability. Comprehensive physical, psychological and social rehabilitation must be continued when the patient leaves hospital, to ensure successful rehabilitation into the community.

\section{Conclusions}

The psychiatrist is a necessary member of the multi-disciplinary team treating SCI patients. While many patients will be seen in primary consultation, rnuch of the psychiatrist's work will be secondary consultation aiding other treating staff to understand the patient's personality and coping strategies thus helping them to most effectively assist the patient in his rehabilitation efforts. Further work and research is required to determine the exact nature and extent of psychiatric morbidity following SCI and in particular the long term sequelae for the SCI patient and his family.

\section{References}

Adams JE, Lindemann E 1974 Coping with long term disability. In: Coehlo GV, Hamburg DA, ADAM JE (eds) Coping and Adaptation. Basic Books Inc., New York, pp. 127-138

Fullerton DT, Harvey RF, Klein MH, et al. 1981 Psychiatric Disorders in Patients with Spinal Cord Injuries. Archives of General Psychiatry 38:1369-1371

JUDD FK, BuRRows GD 1986 Liaison Psychiatry in a Spinal Injuries Unit. Paraplegia 24:6-19

JudD FK, Burrows GD, Brown DJ 1986 Depression in the Acute Phase Following Spinal Cord Injury. Paraplegia 24:358-363

Kahana RJ, Bibring GL 1964 Personality Types in Medical Management. In: Zinberg N (ed) Psychiatry and Medical Practice in a General Hospital. Int. Univ. Press, New York, pp. 108123

LAwSON N 1978 Significant events in the rehabilitation process: The spinal cord patients point of view. Archives of Physical Medicine and Rehabilitation 59:573-579

Mayou R, Hawton K 1986 Psychiatric Disorder in the General Hospital. British fournal of Psychiatry 149:172-190

PoweR PW 1985 Family Coping Behaviours in Chronic Illness: A Rehabilitation Perspective. Rehabilitation Literature 46:77-83 